\title{
Topography-derived variables provide insight into habitat occupancy of a cryptic snake, Bitis atropos
}

\author{
ADRIAAN JORDAAN, ${ }^{* 1}$ (iD NEIL J. L. HEIDEMAN ${ }^{1}$ AND FALKO T. BUSCHKE ${ }^{2,3}$ (D) \\ ${ }^{1}$ Department of Zoology E Entomology, University of the Free State, P.O. Box 339, Bloemfontein, \\ 9300 (Email: bitis182@gmail.com); ${ }^{2}$ Centre for Environmental Management, University of the Free \\ State, Bloemfontein, South Africa; and ${ }^{3}$ Animal Ecology, Global Change and Sustainable Development, \\ KU Leuven, Leuven, Belgium
}

\begin{abstract}
Understanding species' habitat use is fundamental for conservation and management. However, quantifying habitat use for small cryptic species is limited by imperfect detection during field surveys and the lack of habitat data at meaningful spatial scales. Topographically-derived habitat variables from digital elevation models (DEMs) have the potential to overcome these limitations. Here we used DEM-derived topographic variables as fine-scale proxies for abiotic conditions to study site-occupancy patterns of the berg adder (Bitis atropos), a small-bodied cryptic viper. We carried out seven repeated field surveys across 219 hectares in a mountainous protected area in north-eastern South Africa to estimate snake detection probability and occupancy using maximum likelihood methods. Although snakes occurred across a third of the surveyed habitat, they were only detected $40 \%$ of the time during the springtime when detection was highest. Results showed that these snakes preferred north-west facing, mid and upper slopes, which are exposed to afternoon sun and presumably higher ambient energy. Our results demonstrate the value of using DEM-derived topographic variables for ecological studies where habitat data are either unavailable or inappropriate, thereby providing valuable insights into habitat use of cryptic and difficult to detect species.
\end{abstract}

Key words: digital elevation models, imperfect detection, occupancy modelling, site-occupancy, snakes.

\section{INTRODUCTION}

Understanding the factors affecting species' habitat use is not only central to ecology, but also fundamental to guiding conservation and management (Frey et al. 2012; Shelton et al. 2017). Habitat occupancy is generally regulated by various factors, including climate, biotic interactions, and historical processes linked to dispersal (Chen et al. 2013; Cunningham et al. 2016). The extent to which these factors influence occurrence patterns depends on both the scale of assessment and the ecological requirements of a species (Lyet et al. 2013; Cunningham et al. 2016; Michael et al. 2017). For example, environmental factors may explain species diversity at large spatial scales, but the precise quantitative relationship differs amongst taxonomic groups (Hawkins et al. 2003).

The occurrence patterns of ectotherms, like snakes, are especially associated with ambient energy and moisture availability at large scales (Terribile et al. 2009; Lewin et al. 2016). At these spatial scales, studies of species occurrence patterns regularly use global climate datasets, which are typically interpolated at a resolution of 30 arc-seconds $(\sim 1 \mathrm{~km}$;

*Corresponding author.

Accepted for publication April 2021.
Hijmans et al. 2005; Buschke et al. 2015; Garcia et al. 2019). While this resolution is appropriate when studying broad-scale occurrence patterns, it may be too coarse to capture and explain speciesenvironment relationships at smaller scales (Lembrechts et al. 2019).

Many snake species have small geographic distributions and are restricted to topographically heterogeneous landscapes (Turner \& Branch 2014; Behrooz et al. 2015; Yousefi et al. 2015). In such landscapes, local variation in topography creates fine-scale gradients in the structure and the thermal quality of habitat patches (Pringle et al. 2003; Leempoel et al. 2015; Lembrechts et al. 2019; Barton et al. 2019). These important habitat features would be masked by coarse-scale environmental data (Leempoel et al. 2015; Barton et al. 2019). The thermal quality of the local habitat is particularly important for snakes, which rely on behavioural thermoregulation to regulate physiological functions associated with reproduction, development, and locomotion (Webb \& Shine 1998b; Chen et al. 2010; Guillon et al. 2013; Michel et al. 2013). The thermal quality of the landscape not only influences habitat occupancy but may also affect the survival and fitness of individual snakes (Lourdais et al. 2004; Paterson \& Blouin-Demers 2018; Barton et al. 2019). 
The climate data used to infer species distribution patterns at large scales are inappropriate for studying species at smaller scales. Local habitat features need to be classified using fine-resolution data that are more closely aligned to species-specific traits, like dispersal ability, body size, and home range. Finescale environmental data are not readily available, but an alternative approach infers environmental conditions using topographically-derived variables from digital elevation models (DEMs; Leempoel et al. 2015; Wang et al. 2016). DEMs are available at finer resolutions than interpolated climate datasets (Leempoel et al. 2015; Kropáček et al. 2018), so they can be used to capture the underlying biophysical processes linked to species occurrence patterns, especially in topographically heterogeneous landscapes (Leempoel et al. 2015, 2018).

Terrain attributes derived from DEMs can be classified into two categories: primary terrain attributes (e.g. aspect, slope, elevation, and curvature) and secondary terrain attributes (e.g. terrain ruggedness, wetness indices, and temperature indices; Leempoel et al. 2015). Secondary terrain attributes are calculated as derivatives or as combinations of primary terrain attributes (Leempoel et al. 2015). They represent variables of higher complexity and explanatory power and can, therefore, be combined with primary derived terrain attributes and used as proxies for environmental variables (Leempoel et al. 2015).

Despite the potential of using DEM-derived topographic variables such as wetness and temperature indices, linking them to snake occupancy patterns remains difficult. This is largely because snakes are cryptic, have idiosyncratic activity patterns, and often live in difficult-to-survey terrain (Durso et al. 2011; Hansen et al. 2017). These factors limit detectability and create uncertainty when collecting occurrence records (Steen 2010). In light of this, it is unsurprising that snakes are regarded as one of the most difficult-to-study reptile groups (Durso et al. 2011; Sosa \& Schalk 2016). Therefore, any study attempting to link snake occurrence patterns to habitat features must account for imperfect detection by first estimating their detection probability (Mazerolle et al. 2007; Steen 2010). In this sense, occupancy models can be used to quantify site-occupancy patterns of snakes while accounting for imperfect detection (MacKenzie et al. 2002; Tyre et al. 2003; Bonnet et al. 2016; Goldingay 2018).

This study applies an occupancy modelling approach to evaluate habitat use by the berg adder (Bitis atropos), a diurnal, small-bodied viperid with a broad, but fragmented, geographic distribution across southern Africa (Branch 1998; Turner \& Branch 2014). In South Africa, populations along the northeastern escarpment are restricted to moist, highelevation grassland habitat (Haagner \& Hurter 1988).
As for most snake species in Africa, population-level demographic information remains largely unknown (Maritz \& Alexander 2012a, 2012b; Tolley et al. 2019). South African adders (Bitis spp.), particularly the smaller-bodied 'dwarf' members of the genus, are regularly traded on global pet markets (Barlow et al. 2012; Auliya et al. 2016), but the consequences for wild populations are poorly studied. Although the dispersal ability of $B$. atropos is unknown, they are likely to have small home ranges and low vagility, similar to other species of dwarf adders (Maritz \& Alexander 2012a, 2012b; Behrooz et al. 2015; Maritz et al. 2016; Ball et al. 2020).

Like most viperids, $B$. atropos has traits that make it hard to detect (e.g. small body-size, cryptic colouration, and sedentary lifestyles), so they are often overlooked during ecological surveys (Maritz et al. 2016). Therefore, in this study, we carried out repeated surveys to simultaneously estimate siteoccupancy $(\Psi)$ and detection probability $(\rho)$. We then estimated the association between occupancy and topographically-derived habitat variables to determine whether environmental variables affect local-scale habitat occupancy. This approach yielded conclusions about the applicability of using DEMderived topographic variables as substitutes for finescale abiotic variables, as well as insights into the underlying ecology of this cryptic snake species.

\section{MATERIALS AND METHODS}

\section{Study species}

Berg adders (B. atropos) are small (maximum snout-vent length $=490 \mathrm{~mm}$; Branch 1998), diurnal viperids that exhibit colour differences both within and between populations throughout their geographic range (Branch 1998). Individual colouration varies from uniform reddish-brown to olivegrey (Appendix S1) with patterns that blend into the irregular substrate (Broadley 1983; Haagner \& Hurter 1988). Cryptic colouration and small size reduce the detectability of these snakes (Broadley 1983; Haagner \& Hurter 1988; Broadley \& Blaylock 2013). Along the eastern escarpment of southern Africa, B. atropos inhabit cool and moist areas at high elevation in montane grassland habitat where they are often found on rocky slopes basking next to rocks or grass tussocks or sheltering underneath rocks and other loose debris (Jacobsen 1989; Branch 1998; Spawls \& Branch 2020).

Like most viperids, B. atropos are ambush predators that feed on a variety of small vertebrates (lizards, rodents, and amphibians) which are presumably caught from concealed positions (Visser 1979; Branch 1998; Broadley \& Blaylock 2013; Maritz et al. 2016). These snakes are viviparous, and mating presumably takes place during the austral autumn (March-May; Branch 1998). Females give birth to litter sizes varying between 3 and 15 neonates after a prolonged gestation period (c. 130 days) with most births occurring in late-spring (November) to early-summer (December; 

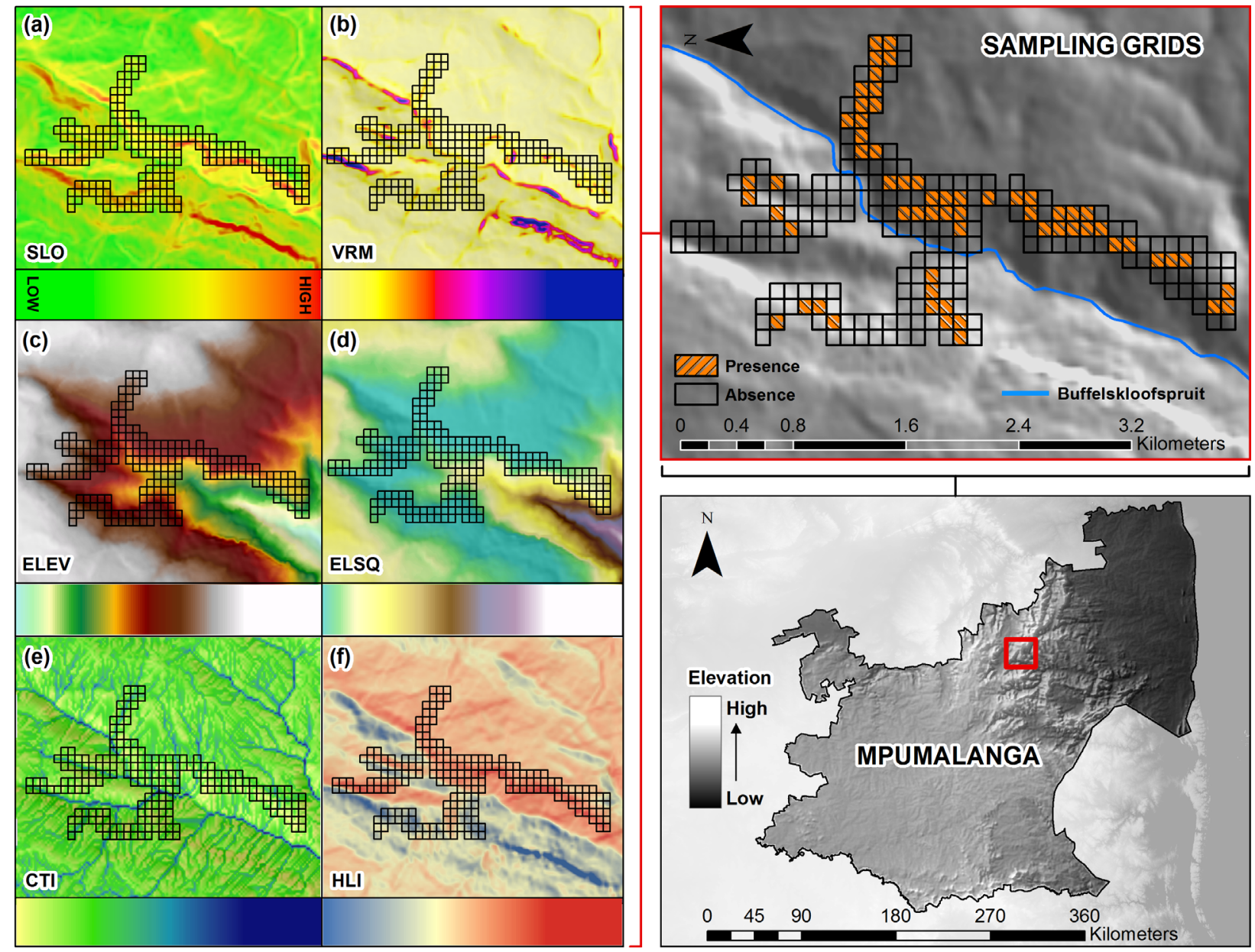

Fig. 1. The location of the study area (top-right panel) in relation to South Africa's Mpumalanga province (bottom-right panel). The top-right map panel shows the cumulative detection/non-detection history for all sampling grids surveyed between 2016 and 2017. Map panels on the left (a-f) show the topography-derived variables that were related to Bitis atropos occupancy patterns at BKPNR. Variables included were: (a) SLO, slope, (b) VRM, Vector Ruggedness Measure, (c) ELEV, elevation, (d) ELSQ, quadratic elevation, (e) CTI, Compound Topographic Index, and (f) HLI, Heat Load Index.

Haagner \& Hurter 1988; Jacobsen 1989). Currently, B. atropos is listed as 'Least Concern' by the IUCN, but this may change because $B$. atropos is a species complex consisting of six distinct evolutionary lineages, which may warrant species status recognition and reassessment of extinction risk (Kelly et al. 2011; Turner \& Branch 2014).

\section{Study area}

This study took place at Buffelskloof Private Nature Reserve (BKPNR; $-25.28^{\circ} \mathrm{S}, 30.51^{\circ} \mathrm{E}$; Fig. 1), a small (c. $1500 \mathrm{ha}$ ), privately-owned and managed protected area on the eastern escarpment of Mpumalanga, South Africa. The reserve is embedded in a matrix of pine (Pinus spp.) and eucalypt (Eucalyptus spp.) plantations, which have replaced large portions of natural vegetation. As a result of historical habitat transformation, the remaining intact habitat of BKPNR primarily consists of a mosaic of moist montane grassland patches, interspersed with small shrub-like trees (Protea spp.) on the upper slopes, and indigenous Afromontane forest belts along the ravines and valley bottoms. BKPNR is topographically complex, ranging in elevation from 1150 to $1850 \mathrm{~m}$ and intersecting three natural vegetation biomes: grassland, savanna, and forest (Mucina \& Rutherford 2006). It receives summer rainfall (October through February), characterised by frequent mist in the mornings and cold winters with occasional frost (Mucina \& Rutherford 2006). Variations in elevation across the reserve directly affect moisture gradients, and the higher northern parts of the reserve are typically wetter than the drier southern parts.

\section{Repeated field surveys}

Surveys were restricted to high-elevation patches of short montane grassland along the northern parts of the reserve 
because this is the known habitat preference of $B$. atropos from the Mpumalanga escarpment (Haagner \& Hurter 1988). We covered this habitat with a regular grid $(100 \times 100 \mathrm{~m})$ consisting of 219 individual sampling units (Fig. 1) using the Grid Index Feature tool in ArcGIS 10.6 (ESRI 2018). The elevation of these units ranged from 1440 to $1830 \mathrm{~m}$. Grid size was selected based on the assumption that $B$. atropos have small home ranges like its small-bodied congener, Bitis schneideri, which on average have home ranges smaller than a hectare $(0.85 \pm 0.09$ ha in males and $0.10 \pm 0.09$ ha in females) (Maritz \& Alexander 2012a).

We carried out field surveys between October 2016 and September 2017 to account for imperfect detection and potential bias of occupancy estimates. In total, seven repeated surveys were carried out during this 12-month period because each survey took between 15 and 20 days to cover all 219 sampling units and surveys were separated by at least one month (mean $\pm \mathrm{SD}=41.1 \pm 6.9$ days). Surveys were performed between $07: 00$ and 18:00 on days with clear overhead conditions and days without heavy rainfall or thunderstorms. Each sampling unit was surveyed according to an active search strategy for a minimum of $20 \mathrm{~min}$. This entailed walking through the site while searching for any loose, non-embedded, physical structures (logs and rocks) in the otherwise homogeneous grassland habitat. We searched for snakes as we moved through the grassland, stopping at loose structures, which were lifted and examined for snakes.

\section{Topography-derived habitat variables}

We used six topographic habitat variables (Fig. 1) derived from a Shuttle Radar Topography Mission (SRTM; Jarvis et al. 2008) DEM at a resolution of 1 arc-second $(\sim 30 \mathrm{~m})$ using ArcGIS 10.6 (ESRI 2018). These variables consisted of primary (Elevation, Quadratic elevation and Slope) and secondary (Vector Ruggedness Measure, Compound Topographic Index and Heat Load Index) terrain attributes selected with the a priori assumption of being important habitat drivers of B. atropos occupancy (Table 1).

Variables associated with primary terrain attributes included slope, elevation, and quadratic elevation. Slope affects the ability of species to move up and down a hillside in response to changing climate conditions and may also affect solar exposure, vegetation productivity and moisture content (Buschke et al. 2020). Elevation determines microclimate conditions, given that temperature-dependent environmental changes are known to be linked to elevation. The quadratic term for elevation was included to account for potential temperature-related mid-elevation (unimodal) effects on occupancy.

The secondary terrain variables represented variables of higher complexity and included compound topographic index (CTI), Vector Ruggedness Measure (VRM), and Heat Load Index (HLI; McCune \& Keon 2002). CTI, which represents a measure of surface moisture, was calculated using the Geomorphometry and Gradient Metrics Toolbox (Evans et al. 2014). VRM, which represents finescale topographic complexity and roughness, was calculated using Benthic Terrain Modeler (Wright et al. 2005) with a $3 \times 3$ neighbourhood to capture fine-scale topographic variability. HLI is a multidimensional metric that integrates slope, aspect (folded around the north-east to south-west line), and latitude to represent a steady-state measure of slope thermal quality based on the potential amount of heat a site receives through incoming solar radiation (McCune \& Keon 2002). The degree of incoming solar radiation a slope receives directly influences temperature and moisture, which might affect the behavioural thermoregulation of snakes. Because this study was conducted in the southern hemisphere, and the insolation characteristics of slopes differ between the northern and southern hemispheres, the HLI equation of McCune and Keon (2002) was adapted by using a modified formula to calculate the folded aspect $($ Folded aspect $=|180-|$ Aspect -315||$)$ where aspect is folded around the south-east north-west line. In the southern hemisphere, north-west facing slopes receive the greatest exposure to incoming solar radiation and therefore represent hotter and drier habitat conditions (McCune \& Keon 2002; McCune 2007). In contrast, south-east facing slopes represent habitats with cooler microclimates and higher levels of moisture (Buschke et al. 2020); this is because they receive considerably less solar exposure, which reduces desiccation rates.

We used Zonal statistics in QGIS (QGIS Development Team 2018) to calculate the mean values of each variable within each of the 219 sampling units. Since the extracted mean values of the predictor variables differed both in units of measure and numerical range, all variables were mean-centred and scaled by standard deviation using the scale function in $\mathrm{R}$ version 3.4.3 ( $\mathrm{R}$ Core Team 2017). To ensure independence among the variables, the effect of collinearity between variable pairs was assessed in $\mathrm{R}$ version 3.4.3 ( $\mathrm{R}$ Core Team 2017) using the corrplot package (Wei et al. 2017). No pairs of variables had Pearson's correlation coefficients $r \geq 10.71$, a threshold commonly used in ecological studies (Dormann et al. 2013), so we retained all explanatory variables in subsequent analyses (Appendix S2).

\section{Data analysis}

To understand how landscape features might affect $B$. atropos occurrence patterns, we used an information-theoretic approach to fit a single-season occupancy model using maximum likelihood (MacKenzie et al. 2002) in $\mathrm{R}$ version 3.4.3 (R Core Team 2017). Occupancy models estimate the outcome of two binomial processes: the probability of a species being present at a site (i.e. occupancy, $\Psi$ ), and, given the species is present, the probability of it being observed in any single visit (i.e. detection probability, $\rho$ ). This entailed fitting single-season occupancy models (occu function in the unmarked package; Fiske \& Chandler 2011) for every combination of explanatory covariates (dredge function in the MuMIn package; Barton 2011). Model support was assessed using sample size corrected Akaike's Information Criterion (AICc; Akaike 1998), and we estimated weighted conditional coefficients (model.avg function in the MuMIn package; Barton 2011) from the subset of models with $\Delta \mathrm{AICc}<2$ (get.models function in the $M u M I n$ 
Table 1. Description of environmental predictors used to model site-occupancy patterns of Bitis atropos at BKPNR

\begin{tabular}{|c|c|c|c|c|c|}
\hline $\begin{array}{l}\text { Terrain } \\
\text { attribute }\end{array}$ & Variable & Description & Units & Ecological justification & Reference(s) \\
\hline \multirow[t]{3}{*}{ Primary } & Elevation & Height above sea level & $\mathrm{m}$ & $\begin{array}{l}\text { Variability in elevation can } \\
\text { facilitate the formation of } \\
\text { distinct microclimates which } \\
\text { may affect habitat } \\
\text { occupancy patterns }\end{array}$ & $\begin{array}{l}\text { Yousefi et al. } \\
\quad(2015)\end{array}$ \\
\hline & $\begin{array}{l}\text { Quadratic } \\
\text { Elevation }\end{array}$ & $\begin{array}{l}\text { Height above sea level } \\
\text { squared }\end{array}$ & $\mathrm{m}^{2}$ & $\begin{array}{l}\text { Habitat occupancy may be } \\
\text { higher at mid-elevations (i.e. } \\
\text { unimodal) }\end{array}$ & $\begin{array}{l}\text { Sadoti et al. } \\
\text { (2013) }\end{array}$ \\
\hline & Slope & $\begin{array}{l}\text { Represents the rate of } \\
\text { change in elevation as } \\
\text { a function of rise over } \\
\text { run to provide a } \\
\text { measure of terrain } \\
\text { steepness }\end{array}$ & degree $\left({ }^{\circ}\right)$ & $\begin{array}{l}\text { Slope inclination can facilitate } \\
\text { or impede movement } \\
\text { between habitat patches and } \\
\text { also affect water availability } \\
\text { and amount of solar } \\
\text { exposure }\end{array}$ & Brito et al. (2011) \\
\hline \multirow[t]{3}{*}{ Secondary } & $\begin{array}{l}\text { Vector } \\
\text { Ruggedness } \\
\text { Measure } \\
\text { (VRM) }\end{array}$ & $\begin{array}{l}\text { A multidimensional } \\
\text { metric of terrain } \\
\text { ruggedness which } \\
\text { incorporates both } \\
\text { slope and aspect as } \\
\text { factors to determine } \\
\text { local variation in } \\
\text { topography }\end{array}$ & Adimensional & $\begin{array}{l}\text { Terrain ruggedness can } \\
\text { influence habitat } \\
\text { characteristics which may } \\
\text { facilitate or impede } \\
\text { behavioural } \\
\text { thermoregulation and } \\
\text { dispersal ability between } \\
\text { habitat patches }\end{array}$ & $\begin{array}{l}\text { Wright et al. } \\
\text { (2005) and } \\
\text { Sappington } \\
\text { et al. }(2007)\end{array}$ \\
\hline & $\begin{array}{l}\text { Compound } \\
\text { Topographic } \\
\text { Index (CTI) }\end{array}$ & $\begin{array}{l}\text { A steady-state measure } \\
\text { of wetness based on } \\
\text { underlying } \\
\text { topography expressed } \\
\text { as a function of slope } \\
\text { and the per unit } \\
\text { width of the upstream } \\
\text { contributing area }\end{array}$ & Adimensional & $\begin{array}{l}\text { Moisture availability affects } \\
\text { both vegetation } \\
\text { characteristics and net } \\
\text { primary productivity which } \\
\text { may influence food } \\
\text { availability }\end{array}$ & $\begin{array}{l}\text { Gessler et al. } \\
\text { (1995) and } \\
\text { Evans et al. } \\
(2014)\end{array}$ \\
\hline & $\begin{array}{l}\text { Heat load index } \\
\quad(\text { HLI })\end{array}$ & $\begin{array}{l}\text { A proxy for the potential } \\
\text { ambient energy a site } \\
\text { receives based on the } \\
\text { underlying } \\
\text { topography of the } \\
\text { landscape }\end{array}$ & Adimensional & $\begin{array}{l}\text { Ambient temperature is } \\
\text { important for optimal } \\
\text { physiological functioning in } \\
\text { ectothermic vertebrates and } \\
\text { a known limiting factor of } \\
\text { snake distributions }\end{array}$ & $\begin{array}{l}\text { McCune and } \\
\text { Keon (2002) } \\
\text { and Lewin } \\
\text { et al. (2016) }\end{array}$ \\
\hline
\end{tabular}

package; Barton 2011). There were no indications for lack of fit for the full model according to sum of squared errors $\left(\mathrm{SSE}=114, \mathrm{SSE}_{\mathrm{sim}}=112.42 \pm 12.0 ; P=0.538\right)$, Pearson chi-squared $\left(\chi^{2}=1316, \chi_{\text {sim }}^{2}=1406 \pm 102.4 ; P=0.846\right)$ or Freeman-Tukey chi-squared tests $\left(\chi^{2}=174\right.$, $\left.\chi_{\text {sim }}^{2}=171.20 \pm 16.2 ; P=0.500\right)$.

In the models, we assumed that the probability of detecting $(\rho)$ a snake depended on the time of year but was constant across sampling sites regardless of topographical variables because of the homogeneity of grassland habitat and the standardised protocol used for field surveys. Observer bias did not affect detection probability because all surveys were conducted by the same person. We included the Julian days (i.e. integers between 1 and 365 for days of the year) as covariates for detection probability and used sinand cosine-transformations to create circular variables for the season: $\sin$ (Julian day $* 360 / 365 *$ pi/180) and cosine (Julian day $* 360 / 365 *$ pi/180), where directional degrees are converted to radians. We included the six topographical variables (Table 1) as covariates for occupancy $(\Psi)$.
Two important assumptions of single-season occupancy models are that there is no false detection (i.e. species misidentification) and that populations (i.e. occupancy of sampling units) are closed during surveys (MacKenzie et al. 2002; Durso et al. 2011). We assumed that there were no false detections because our survey methods always placed us in direct contact with specimens so that we could see the distinct morphological features of B. atropos clearly. We assumed that $B$. atropos has low vagility and a small home range like congeneric species (Maritz \& Alexander 2012a), which meets the assumption of closure. Even when there might be movement between sampling units, such as by roaming males during the mating season, the closure assumption can be relaxed if movement between sampling units is approximately random (Mazerolle et al. 2007; Jeffress et al. 2011). Although sites were spatially autocorrelated, we did not account for this explicitly in our models because the information-theoretic approach did not test for statistical significance (which is affected by the nonindependence of samples). Instead, the information- 
theoretic approach was used to estimate model coefficients, which are generally unaffected by spatial autocorrelation in gridded data (Hawkins et al. 2007).

\section{RESULTS}

Bitis atropos were detected at 62 of the 219 sampling units, resulting in a naïve occupancy of 0.283 and an estimated occupancy of $0.352 \pm 0.05$ SE under average conditions. These adders were recorded only once in 31 of the sampling units, twice in 12 units and three or more times in 19 units. Detection probability varied through the year between $0.119 \pm 0.03$ $\mathrm{SE}$ and $0.407 \pm 0.04 \mathrm{SE}$ and was highest during the springtime (September-October: Fig. 2).

Out of 256 combinations of occupancy and detection covariates, none of the nine best-supported models with $\triangle \mathrm{AICc}<2$ included slope as a covariate (Fig. 2a; Table 2). By contrast, the HLI was the only occupancy covariate included in all nine bestsupported subset models (Fig. 3a). Occupancy was positively associated with the HLI (coefficient estimate $=0.437 \pm 0.18 \mathrm{SE}$; Fig. $3 \mathrm{f}$ ) as $B$. atropos occupancy generally increased on north-west facing slopes that have higher HLI values. Elevation and quadratic elevation were retained in seven and six of the bestsupported models, respectively, including the model with the lowest AICc. Model coefficients showed that snakes preferred mid- (coefficient estimate $=-0.283$ $\pm 0.16 \mathrm{SE}$; Fig. 3c) to upper slopes (coefficient

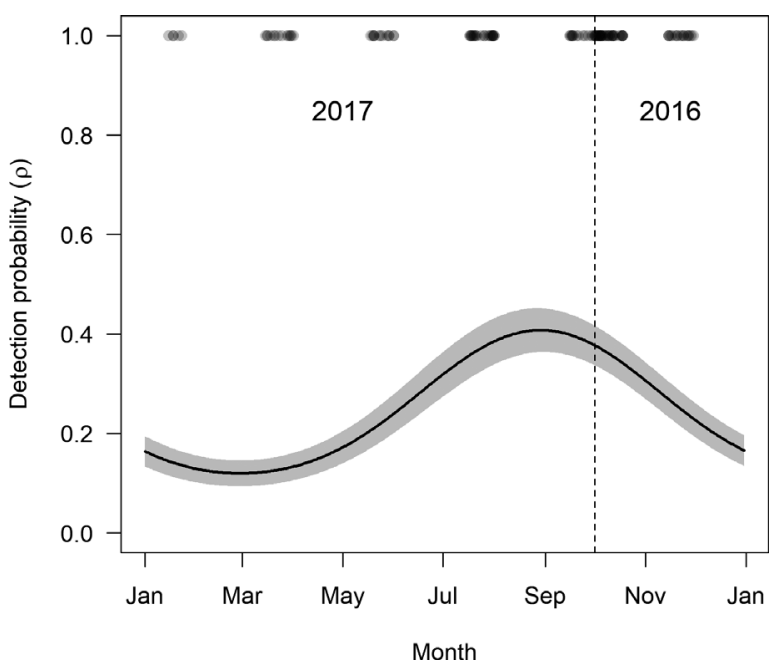

Fig. 2. Seasonal variation in detection probability $(\rho)$ of Bitis atropos during a calendar year. The black lines and the shaded areas represent the mean and standard errors of predicted detection probability. The surveys began in October 2016 and ended in September 2017 as denoted by the vertical dashed line, but predictions are circular and insensitive to starting date (i.e. values for January on the left and right of the figure are identical). estimate $=0.327 \pm 0.18$ SE; Fig. 3b). The VRM (Fig. 3d) and the compound topographic index (Fig. 3e) were included in five and three, respectively, of the best-supported models (Fig. 3a), and were negatively associated with occupancy (VRM coefficient estimate $=-0.239 \pm 0.18$ SE; CTI coefficient estimate $=-0.223 \pm 0.18 \mathrm{SE}$ ).

\section{DISCUSSION}

Snakes are often the most challenging reptiles to study because they are difficult to detect and regularly occur in habitats that are difficult-to-survey (Durso et al. 2011; Sosa \& Schalk 2016). In this study, we assessed the local-scale habitat occupancy of a small-bodied montane viperid, B. atropos, and found that its occupancy patterns were non-random and associated with landscape characteristics linked to higher ambient energy. This demonstrates the value of using DEM-derived topographic variables for ecological studies where habitat data are either unavailable or inappropriate.

Heat load index was positively associated with B. atropos occupancy. This suggests that this snake prefers habitats with particular thermal qualities. Specifically, occupancy was higher on a north-west facing slopes that receive warm midday and afternoon sunshine and, therefore, more incoming solar radiation and higher ambient energy (Clarke \& Gaston 2006). These affinities for topographic areas with higher ambient energy is to be expected because thermoregulation is considered as the most important factor for squamate habitat use (Blouin-Demers \& Weatherhead 2001, 2002). Viviparous snakes, such as $B$. atropos, must maintain warm body temperatures during gestation and the fitness and phenotype of their offspring are directly affected by the temperatures experienced during development (BlouinDemers \& Weatherhead 2001). Our findings are consistent with those from other species that depend on thermally conducive habitat related to behavioural thermoregulation (Weatherhead \& Charland 1985; Blouin-Demers \& Weatherhead 2001, 2008). For example, Halliday and Blouin-Demers (2016) showed how patches with a high thermal quality provided increased reproductive outputs and growth rates in colubrid snakes. Similar trends were shown for black rat snakes (Elaphe obsoleta obsoleta), which actively selected habitat edges with greater exposure to incoming solar radiation for thermoregulatory reasons (Weatherhead \& Charland 1985; BlouinDemers \& Weatherhead 2001).

In general, the thermal requirements of snakes are more pronounced in thermally challenging temperate regions (e.g. Blouin-Demers \& Weatherhead 2001; Halliday \& Blouin-Demers 2016). At lower latitudes, 
Table 2. Variable combinations of subset models used for multi-model averaging

\begin{tabular}{|c|c|c|c|c|c|}
\hline Detection $(\rho)$ covariates & Occupancy $(\psi)$ covariates & Log-likelihood & $\mathrm{AICc}$ & $\Delta \mathrm{AICc}$ & Weight \\
\hline $\sin$ (Day) $+\operatorname{cosine}($ Day) & $\mathrm{Elev}^{2}+\mathrm{Elev}+\mathrm{HLI}$ & -369.59 & 753.72 & 0.00 & 0.19 \\
\hline $\sin$ (Day) $+\operatorname{cosine}$ (Day) & $\mathrm{Elev}^{2}+\mathrm{Elev}+\mathrm{HLI}+\mathrm{VRM}$ & -368.78 & 754.25 & 0.53 & 0.14 \\
\hline $\sin$ (Day) $+\operatorname{cosine}$ (Day) & $\mathrm{CTI}+\mathrm{Elev}^{2}+\mathrm{Elev}+\mathrm{HLI}$ & -368.81 & 754.30 & 0.59 & 0.14 \\
\hline $\sin$ (Day) + cosine(Day) & $\mathrm{CTI}+\mathrm{Elev}^{2}+\mathrm{Elev}+\mathrm{HLI}+\mathrm{VRM}$ & -367.97 & 754.80 & 1.09 & 0.11 \\
\hline $\sin$ (Day) $+\operatorname{cosine}$ (Day) & $\mathrm{Elev}^{2}+\mathrm{HLI}$ & -371.32 & 755.04 & 1.32 & 0.10 \\
\hline $\sin$ (Day) $+\operatorname{cosine}$ (Day) & $\mathrm{Elev}+\mathrm{HLI}+\mathrm{VRM}$ & -370.36 & 755.24 & 1.53 & 0.09 \\
\hline $\sin$ (Day) + cosine(Day) & Elev + HLI & -371.45 & 755.30 & 1.59 & 0.08 \\
\hline $\sin$ (Day) + cosine(Day) & $\mathrm{Elev}^{2}+\mathrm{HLI}+\mathrm{VRM}$ & -370.49 & 755.51 & 1.79 & 0.08 \\
\hline $\sin$ (Day) $+\operatorname{cosine}$ (Day) & $\mathrm{CTI}+\mathrm{Elev}+\mathrm{HLI}+\mathrm{VRM}$ & -369.47 & 755.62 & 1.91 & 0.07 \\
\hline
\end{tabular}

CTI, compound topographic index; Day, Julian day of the year; Elev, elevation; Elev $^{2}$, quadratic elevation; HLI, heat load index; VRM, vector ruggedness measure.
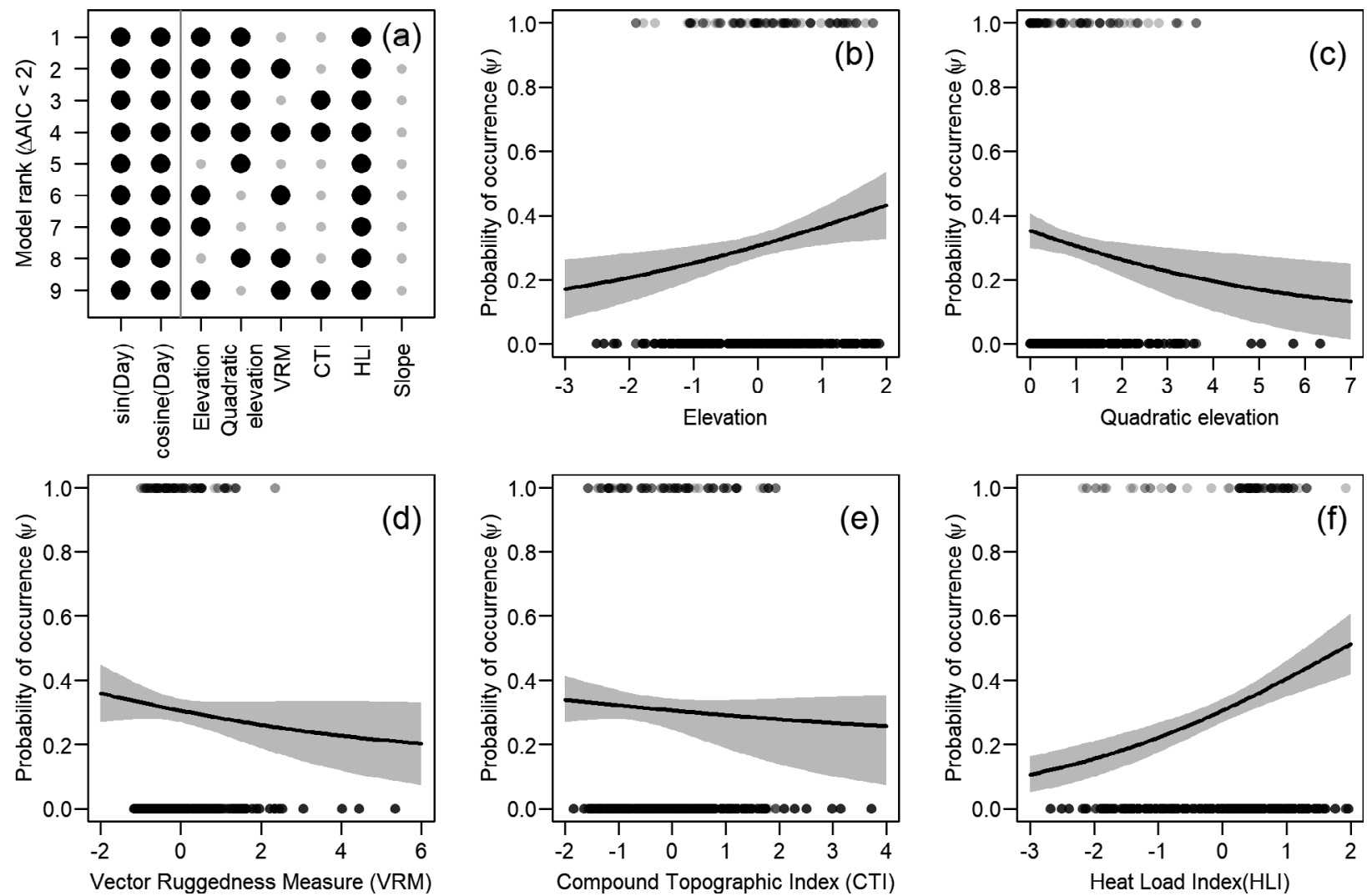

Fig. 3. Predicted relationships based on multi-model inference between Bitis atropos occupancy $(\Psi)$ and topography-derived covariates. (a) The combination of covariates in the best-supported models $(\Delta \mathrm{AICc}<2)$ where large black circles denote the inclusion of the covariate in the model and small grey circles denotes its absence. The day covariate was associated with detection probability $(\rho)$ and, with the exception of slope, occupancy covariate abbreviations correspond to the horizontal axes of panels b-f. The predicted association between occupancy and (b) elevation, (c) quadratic elevation, (d) Vector Ruggedness Measure, (e) Compound Topographic Index and (f) Heat Load Index. The black lines are the predicted relationships based on mean coefficients while keeping the other covariates at their mean values, and the shaded areas are based on the standard errors around mean coefficients.

snakes might adapt their behaviour to avoid excessively hot temperatures (e.g. Llewelyn et al. 2005) or be more sensitive to moisture availability than to temperature (e.g. Brown \& Shine 2006). The B. atropos from mountainous habitat in this study seems to be more like snakes in temperate regions, even though they occur at tropical latitudes. This is understandable because this high-lying region has a mean annual temperature of approximately $14^{\circ} \mathrm{C}$, which could be thermally challenging for an ectothermic species. 
Habitat heterogeneity is generally considered an important factor for micro-habitat selection in snakes (Blouin-Demers \& Weatherhead 2001, 2008; Harvey \& Weatherhead 2010; Steen et al. 2014), but we found a negative association between occupancy and the VRM. This suggests that at the scale of this study, thermal properties of the broader landscape are more strongly associated with occupancy than the availability of local habitat heterogeneity needed for microhabitat selection. Nevertheless, the factors influencing habitat use might not be consistent across scales (McGill 2010; Buschke et al. 2014), so it is important to match the scale of predictor data to the ecology of the species when studying habitat preferences (Guisan \& Thuiller 2005). While occupancy could be linked to broader-scale thermoregulation, our results suggest that water availability is less important for explaining $B$. atropos occupancy. These snakes preferred mid-toupper slopes, which are presumably drier than lowlands; and occupancy was also negatively associated with the compound topographic index, a proxy of water accumulation in the landscape.

Snakes have traits that limit their detection during field surveys, so assessments of habitat use are difficult without considering imperfect detection (Mazerolle et al. 2007; Steen 2010). Our results confirmed this by showing that $B$. atropos detection probability was low (between 0.12 and 0.4 ) and seasonally variable. Specifically, we found that detection probability was highest during austral spring (September-October) and lowest in the late-summer/early-autumn (February-March), which is unsurprising considering that detectability of snakes is known to vary seasonally (Kery 2002). Although the mechanism responsible for regulating this variability in detection probability remains uncertain, it is likely due to a combination of increasing springtime temperatures and the onset of the summer rainy season. Despite often being found at high population densities (Phelps 2010), these snakes are easily missed during surveys due to their cryptic colouration and small body size. Therefore, population monitoring for this species should prioritise early springtime surveys when snakes are more likely to be found underneath rocks prior to dispersing during the active season.

Low detection probability for $B$. atropos is comparable to those reported for viperids and other snake species. For example, detection probabilities for two North American viperid species (Sistrurus catenatus and Crotalus adamanteus) were also lower than 0.3 (Harvey 2005; Bauder et al. 2017), while the detection probability for the cottonmouth viper, $A g k$ istrodon piscivorus, was only 0.03 (Durso et al. 2011). Our results reiterate the difficulty of studying vipers in natural settings due to the challenges of detecting these snakes (Harvey 2005; Maritz et al. 2016; Bauder et al. 2017). Although other snake families might have detection probabilities slightly higher than vipers, most snakes have low detection rates between 0.1 and 0.46 (Durso et al. 2011; Goldingay 2018).

Our study provides insights into the habitat requirements of $B$. atropos, a species difficult to detect and monitor. We were able to couple occupancy to landscape features using DEM-derived topographic variables as environmental proxies in a way that provide meaningful biological insights. In this regard, DEM-derived topographic variables can be valuable proxies when environmental data are unavailable or at inappropriate scales. However, our repeated surveys have shed light on the imperfect detection of cryptic species, where specimens are more likely to be missed than recorded in their preferred habitats. Therefore, although DEM-derived topography variables can stand in for sparse environmental data, thorough field surveys remain essential when studying species habitat use.

\section{ACKNOWLEDGEMENTS}

We are grateful to Ross Goldingay, Nigel Andrew, and two anonymous reviewers for their helpful comments and suggestions that improved this manuscript. We would like to thank the management and staff of Buffelskloof Private Nature Reserve for their hospitality and logistical support provided during fieldwork. Furthermore, we would also like to thank Simonet de Villiers, Luke Verburgt and Ursula Verburgt (Enviro-Insight) for support during fieldwork. Johan Marais from the African Snake Bite Institute (ASI) is thanked for the sponsorship of snake handling equipment. $\mathrm{NH}$ was supported by a National Research Foundation (NRF) grant (no. IFR150216114248) and AJ was supported by an NRF Innovation Scarce Skills Development Masters Scholarship.

\section{AUTHOR CONTRIBUTIONS}

Adriaan Jordaan: Conceptualization (equal); Formal analysis (equal); Investigation (equal); Methodology (equal); Writing-original draft (lead); Writing-review \& editing (equal). Neil J. L. Heideman: Project administration (equal); Supervision (equal); Writingreview \& editing (equal). Falko T. Buschke: Conceptualization (equal); Formal analysis (equal); Investigation (equal); Methodology (equal); Supervision (equal); Writing-review \& editing (equal).

\section{CONFLICT OF INTEREST}

The authors declare no conflict of interest. 


\section{COMPLIANCE WITH ETHICAL STANDARDS}

Permits to carry out this research was obtained from the Mpumalanga Tourism and Parks Agency (MTPA) under permit no. MPB. 5571/2, and ethical clearance was provided by the University of the Free State's Animal Ethics Committee (clearance no. UFS-AED2016/0115).

\section{REFERENCES}

Akaike H. (1998) Information theory and an extension of the maximum likelihood principle. In: Selected papers of Hirotugu Akaike (eds E. Parzen, K. Tanabe \& K. Genshiro) pp. 199-213. Springer, New York.

Auliya M., Altherr S., Ariano-Sanchez D. et al. (2016) Trade in live reptiles, its impact on wild populations, and the role of the European market. Biol. Conserv. 204, 103-19.

Ball S., Hand N., Willman F. et al. (2020) Genetic and demographic vulnerability of adder populations: results of a genetic study in mainland Britain. PLoS One 15, 1-25.

Barlow A., Grail W., de Bruyn M. \& Wüster W. (2012) Anonymous nuclear markers for the African adders (Serpentes: Viperidae: Bitis). Conserv. Genet. Resour. 4, 967-9.

Bartoń K. (2011) MuMIn: multi-model inference. R package version 1.0.0 [Cited 10 May 2020.] Available from URL: http://CRAN.R-project.org/package=MuMIn

Barton M. G., Clusella-Trullas S. \& Terblanche J. S. (2019) Spatial scale, topography and thermoregulatory behaviour interact when modelling species' thermal niches. Ecography 42, 376-89.

Bauder J. M., Stevenson D. J., Sutherland C. S. \& Jenkins C. L. (2017) Occupancy of potential overwintering habitat on protected lands by two imperiled snake species in the coastal plain of the southeastern United States. F. Herpetol. 51, 73-88.

Behrooz R., Kaboli M., Nourani E. et al. (2015) Habitat modeling and conservation of the endemic latifi's viper (Montivipera latifii) in Lar National Park, Northern Iran. Herpetol. Conserv. Biol. 10, 572-82.

Blouin-Demers G. \& Weatherhead P. J. (2001) Habitat use by black rat snakes (Elaphe obsoleta obsoleta) in fragmented forests. Ecology 82, 2882-96.

Blouin-Demers G. \& Weatherhead P. J. (2002) Habitat-specific behavioural thermoregulation by black rat snakes (Elaphe obsoleta obsoleta). Oikos 97, 59-68.

Blouin-Demers G. \& Weatherhead P. J. (2008) Habitat use is linked to components of fitness through the temperaturedependence of performance in ratsnakes (Elaphe obsoleta). Isr. F. Ecol. Evol. 54, 361-72.

Bonnet X., Lecq S., Lassay J. 1. et al. (2016) Forest management bolsters native snake populations in urban parks. Biol. Conserv. 193, 1-8.

Branch W. R. (1998) A Photographic Guide to Snakes and Other Reptiles of Southern Africa. Struik, Cape Town.

Brito J. C., Fahd S., Geniez P., Martínez-Freiría F., Pleguezuelos J. M. \& Trape J.-F. (2011) Biogeography and conservation of viperids from North-West Africa: an application of ecological niche-based models and GIS. $\mathcal{F}$. Arid Environ. 75, 1029-37.

Broadley D. G. (1983) FitzSimons' Snakes of Southern Africa. Delta Books, Johannesburg.
Broadley D. G. \& Blaylock R. (2013) Snakes of Zimbabwe and Botswana. Chimaira, Frankfurt.

Brown G. P. \& Shine R. (2006) Why do tropical animals reproduce seasonally? Testing hypotheses on an Australian snake. Ecology 87, 133-43.

Buschke F. T., Brendonck L. \& Vanschoenwinkel B. (2014) Difference between regional and biogeographi species pools highlight the need for multi-scale theories in macroecology. Front. Biogeogr. 6, 173-84.

Buschke F. T., Coetzer C., Pinceel T. et al. (2020) Mountains and rocky outcrops as ecological refuges in a high biodiversity working landscape. Biol. Conserv. 250, 108759.

Buschke F. T., De Meester L., Brendonck L. \& Vanschoenwinkel B. (2015) Partitioning the variation in African vertebrate distributions into environmental and spatial components - exploring the link between ecology and biogeography. Ecography 38, 450-61.

Chen Y. H., Huang S. P., Chang M. H. \& Tu M. C. (2010) Thermal effects on embryogenesis and hatchlings of the grass lizard Takydromus stejnegeri (Squamata: Lacertidae) and implications of their potential for limiting its altitudinal distribution in Taiwan. Zool. Stud. 49, 374-80.

Chen Y. H., Tu M. C. \& Huang S. P. (2013) Synergistic limits to the altitudinal distribution of a high-altitude lizard, Takydromus hsuehshanensis. Zoolog Sci. 30, 15-20.

Clarke A. \& Gaston K. J. (2006) Climate, energy and diversity. Proc. R. Soc. B 273, 2257-66.

Cunningham H. R., Rissler L. J., Buckley L. B. \& Urban M. C. (2016) Abiotic and biotic constraints across reptile and amphibian ranges. Ecography 39, 1-8.

Dormann C. F., Elith J., Bacher S. et al. (2013) Collinearity: a review of methods to deal with it and a simulation study evaluating their performance. Ecography 36, 27-46.

Durso A. M., Willson J. D. \& Winne C. T. (2011) Needles in haystacks: estimating detection probability and occupancy of rare and cryptic snakes. Biol. Conserv. 144, 1508-15.

ESRI (2018) ArcGIS Desktop. Environmental Systems Research Institute, Redlands.

Evans J. S., Oakleaf J., Cushman S. A. \& Theobald D. (2014) An ArcGIS toolbox for surface gradient and geomorphometric modeling. Version 2.0-0 [Cited 14 January 2019.] Available from URL: http://evansmurphy. wix.com/evansspatial

Fiske I. J. \& Chandler R. B. (2011) Unmarked: an R package for fitting hierarchical models of wildlife occurrence and abundance. F. Stat. Softw. 43, 1-23. https://doi.org/10. 18637/jss.v043.i10.

Frey S. J. K., Strong A. M. \& Mcfarland K. P. (2012) The relative contribution of local habitat and landscape context to metapopulation processes: a dynamic occupancy modeling approach. Ecography 35, 581-9.

Garcia R. A., Allen J. L. \& Clusella-Trullas S. (2019) Rethinking the scale and formulation of indices assessing organism vulnerability to warmer habitats. Ecography 42, 1024-36.

Gessler P. E., Moore I. D., Mckenzie N. J. \& Ryan P. J. (1995) Soil-landscape modelling and spatial prediction of soil attributes. Int. F. Geogr. Inf. Syst. 9, 421-32.

Goldingay R. L. (2018) Persistence of Australia's most threatened snake (Hoplocephalus bungaroides) in Australia's oldest National Park. F. Zool. 304, 202-9.

Guillon M., Guiller G., Denardo D. F. \& Lourdais O. (2013) Microclimate preferences correlate with contrasted evaporative water loss in parapatric vipers at their contact zone. Can. F. Zool. 92, 81-6. 
Guisan A. \& Thuiller W. (2005) Predicting species distribution: offering more than simple habitat models. Ecol. Lett. 8, 993-1009.

Haagner G. V. \& Hurter J. (1988) Additional distribution records of the berg adder Bitis atropos in the south-eastern Transvaal and Swaziland. Koedoe 31, 71-6.

Halliday W. D. \& Blouin-Demers G. (2016) Differential fitness in field and forest explains density-independent habitat selection by gartersnakes. Oecologia 181, 841-51.

Hansen E. C., Scherer R. D., FleishmanE D. B. G. \& Krolick D. (2017) Relations between environmental attributes and contemporary occupancy of threatened giant gartersnakes (Thamnophis gigas). F. Herpetol. 51, 274-83.

Harvey D. S. (2005) Detectability of a large-bodied snake (Sistrurus c. catenatus) by time-constrained searching. Herpetol. Rev. 4, 413.

Harvey D. S. \& Weatherhead P. J. (2010) Habitat selection as the mechanism for thermoregulation in a northern population of massasauga rattlesnakes (Sistrurus catenatus). Ecoscience 17, 411-9.

Hawkins B. A., Diniz-Filho J. A. F., Bini L. M., De Marco P. \& Blackburn T. M. (2007) Red herrings revisited: spatial autocorrelation and parameter estimation in geographical ecology. Ecography 30, 375-84.

Hawkins B. A., Field R., Cornell H. V. et al. (2003) Energy, water, and broad-scale geographic patterns of species richness. Ecology 84, 3105-17.

Hijmans R. J., Cameron S. E., Parra J. L., Jones P. G. \& Jarvis A. (2005) Very high resolution interpolated climate surfaces for global land areas. Int. F. Climatol. 25, 196578

Jacobsen N. H. G. (1989) A herpetological survey of the Transvaal. $\mathrm{PhD}$ thesis, University of Natal, Durban.

Jarvis A., Reuter H. I., Nelson A. \& Guevara E. (2008) Holefilled SRTM for the globe, Version 4. CGIAR-CSI SRTM 90m Database.

Jeffress M. R., Paukert C. P., Sandercock B. K. \& Gipson P. S. (2011) Factors affecting detectability of river otters during sign surveys. F. Wildl. Manage. 75, 144-50.

Kelly C. M. R., Branch W. R., Villet M. H. \& Barker N. P. (2011) Adders and afromontane phylogeography: the Great Escarpment and Cape Fold Mountains as a speciation hot-bed for dwarf Bitis. In: Proceedings of the Congresses of the Southern African Society for Systematic Biology, Southern African Society for Systematic Biology (eds M. H. Villet \& K. L. Crous) p. 52. Grahamstown.

Kery M. (2002) Inferring the absence of a species: a case study of snakes. F. Wildl. Manage. 66, 330.

Kropáček J., Moudrá L., Wild J. et al. (2018) On the use of global DEMs in ecological modelling and the accuracy of new bare-earth DEMs. Ecol. Modell. 383, 3-9.

Leempoel K., Parisod C., Geiser C., Daprà L., Vittoz P. \& Joost S. (2015) Very high-resolution digital elevation models: are multi-scale derived variables ecologically relevant? Methods Ecol. Evol. 6, 1373-83.

Leempoel K., Parisod C., Geiser C. \& Joost S. (2018) Multiscale landscape genomic models to detect signatures of selection in the alpine plant Biscutella laevigata. Ecol. Evol. 8, 1794-806.

Lembrechts J. J., Nijs I. \& Lenoir J. (2019) Incorporating microclimate into species distribution models. Ecography 42, 1267-1279.

Lewin A., Feldman A., Bauer A. M. et al. (2016) Patterns of species richness, endemism and environmental gradients of African reptiles. F. Biogeogr. 43, 2380-90.
Llewelyn J., Shine R. \& Webb J. K. (2005) Theral regime and diel activity patterns of four species of small elapid snakes from south-eastern Australia. Aus. F. Zool. 53, 1-8.

Lourdais O., Shine R., Bonnet X., Guillon M. \& Naulleau G. (2004) Climate affects embryonic development in a viviparous snake, Vipera aspis. Oikos 104, 551-60.

Lyet A., Thuiller W., Cheylan M. \& Besnard A. (2013) Finescale regional distribution modelling of rare and threatened species: bridging GIS tools and conservation in practice. Divers. Distrib. 19, 651-63.

MacKenzie D. I., Nichols J. D., Lachman G. B., Droege S., Royle A. A. \& Langtimm C. A. (2002) Estimating site occupancy rates when detection probabilities are less than one. Ecology 83, 2248-55.

Maritz B. \& Alexander G. J. (2012a) Dwarfs on the move: spatial ecology of the world's smallest viper, Bitis schneideri. Copeia 2012, 115-20.

Maritz B. \& Alexander G. J. (2012b) Population density and survival estimates of the African viperid, Bitis schneideri. Herpetologica 68, 195-202.

Maritz B., Penner J., Martins M. et al. (2016) Identifying global priorities for the conservation of vipers. Biol. Conserv. 204, 94-102.

Mazerolle M. J., Bailey L. L., Kendall W. L., Royle J. A., Converse S. J. \& Nichols J. D. (2007) Making great leaps forward: accounting for detectability in herpetological field studies. F. Herpetol. 41, 672-89.

McCune B. (2007) Improved estimates of incident radiation and heat load using non-parametric regression against topographic variables. F. Veg. Sci. 18, 751-4.

McCune B. \& Keon D. (2002) Equations for potential annual direct incident radiation and heat load. f. Veg. Sci. 13, 603-6.

McGill B. J. (2010) Matters of scale. Science 328, 575-6.

Michael D. R., Ikin K., Crane M., Okada S. \& Lindenmayer D. B. (2017) Scale-dependent occupancy patterns in reptiles across topographically different landscapes. Ecography 40, 415-24.

Michel C. L., Pastore J. H. \& Bonnet X. (2013) Impact of cool versus warm temperatures on gestation in the aspic viper (Vipera aspis). Comp. Biochem. Physiol. Part A: Mol. Integr. Physiol. 165, 338-42.

Mucina L. \& Rutherford M. C. (2006) The Vegetation of South Africa, Lesotho and Swaziland. Strelitzia 19. South African National Biodiversity Institute (SANBI), Pretoria.

Paterson J. E. \& Blouin-Demers G. (2018) Tree lizard (Urosaurus ornatus) growth decreases with population density, but increases with habitat quality. F. Exp. Zool. Part A: Ecol. Integr. Physiol. 329, 527-35.

Phelps T. (2010) Old World Vipers: A Natural History of the Azemiopinae and Viperinae. Chimaira, Frankfurt.

Pringle R. M., Webb J. K. \& Shine R. (2003) Canopy structure, microclimate, and habitat selection by a nocturnal snake, Hoplocephalus bungaroides. Ecology 84, 2668-79.

Qgis Development Team (2018) QGIS Geographic Information System. Open Source Geospatial Foundation Project, Madeira.

R Core Team (2017) R: A Language and Environment for Statistical Computing. $\mathrm{R}$ Foundation for Statistical Computing, Vienna.

Sadoti G., Zuckerberg B., Jarzyna M. A. \& Porter W. F. (2013) Applying occupancy estimation and modelling to the analysis of atlas data. Divers. Distrib. 19, 804-14.

Sappington J. M., Longshore K. M. \& Thompson D. B. (2007) Quantifying landscape ruggedness for animal 
habitat analysis: a case study using bighorn sheep in the Mojave Desert. f. Wildl. Manage 71, 1419-26.

Shelton M. B., Goldingay R. L. \& Phillips S. S. (2017) Population ecology of a cryptic arboreal snake (Hoplocephalus bitorquatus). Aust. F. Zool. 65, 383-90.

Sosa R. \& Schalk C. M. (2016) Seasonal activity and species habitat guilds influence road-kill patterns of neotropical snakes. Trop. Conserv. Sci. 9, 194008291667966.

Spawls S. \& Branch B. (2020) The Dangerous Snakes of Africa. Bloomsbury Publishing, London.

Steen D. A. (2010) Snakes in the grass: secretive natural histories defy both conventional and progressive statistics. Herpetol. Conserv. Biol. 5, 183-8.

Steen D. A., Mcclure C. J. W., Brock J. C. et al. (2014) Snake co-occurrence patterns are best explained by habitat and hypothesised effects of interspecific interactions. F. Anim. Ecol. 83, 286-95.

Terribile L. C., Olalla-Tárraga M. Á., Morales-Castilla I. et al. (2009) Global richness patterns of venomous snakes reveal contrasting influences of ecology and history in two different clades. Oecologia 159, 617-26.

Tolley K. A., Weeber J., Maritz B. et al. (2019) No safe haven: protection levels show imperilled South African reptiles not sufficiently safe-guarded despite low average extinction risk. Biol. Conserv. 233, 61-72.

Turner A. A. \& Branch W. R. (2014) Family viperidae. In: Attas and Red List of the Reptiles of South Africa, Lesotho and Swaziland (eds M. F. Bates, W. R. Branch, A. M. Bauer, M. Burger, J. Marais, G. J. Alexander \& M. S. de Villiers) p. Suricata 1. South African National Biodiversity Institute, Pretoria.

Tyre A. J., Tenhumberg B., Field S. A., Niejalke D., Parris K. \& Possingham H. P. (2003) Improving precision and reducing bias in biological surveys: estimating falsenegative error rates. Ecol. Appl. 13, 1790-801.

Visser J. (1979) Common Snakes of South Africa. Purnell, Cape Town.
Wang G., Wang T., Liu S. et al. (2016) Using DEM to predict Abies faxoniana and Quercus aquifolioides distributions in the upstream catchment basin of the Min River in southwest China. Ecol. Indic. 69, 91-9.

Weatherhead P. J. \& Charland M. B. (1985) Habitat selection in an Ontario population of the snake, Elaphe obsoleta. $\mathcal{F}$. Herpetol. 19, 12.

Webb J. K. \& Shine R. (1998b) Using thermal ecology to predict retreat-site selection by an endangered snake species. Biol. Conserv. 86, 233-42.

Wei T., Simko V., Levy M., Xie Y., Jin Y. \& Zemla J. (2017) Package 'corrplot'. Statistician 56, 316-324.

Wright D. J., Lundblad E. R., Larkin E. M., Rinehart R. W., Murphy J., Cary-Kothera L. \& Draganov K. (2005) Benthic Terrain Modeler (BTM) extension for ArcGIS 8. $\mathrm{x}$ and 9. $\mathrm{x}$, ver. 1.0 [Cited 14 January 2019.] Available from URL: http://www.csc.noaa.gov/products/btm/

Yousefi M., Ahmadi M., Nourani E. et al. (2015) Upward altitudinal shifts in habitat suitability of mountain vipers since the last glacial maximum. PLoS One 10 1-14.

\section{SUPPORTING INFORMATION}

Additional supporting information may/can be found online in the supporting information tab for this article.

Appendix S1. Phenotypic colour variation of Bitis atropos individuals found during surveys within the study area.

Appendix S2. Matrix of pairwise correlation coefficients for DEM-derived environmental variables used in predicting occupancy relationships for berg adders. 